\title{
Comparison of vitamin D profile between patients with inflammatory and non-inflammatory rheumatic diseases
}

\author{
(1) Nihan Cüzdan', (1) İlke Coşkun Benlidayı², (1) Sibel Başaran², (1) Tunay Sarpel² \\ ${ }^{1}$ Balikesir Ataturk City Hospital, Clinic of Rheumatology, Balikesir, Turkey \\ ${ }^{2}$ Cukurova University Faculty of Medicine, Department of Physical Medicine and Rehabilitation, Adana, Turkey
}

\section{Date submitted:}

13.04.2020

Date accepted:

08.06.2020

Online publication date:

15.12.2020

\section{Corresponding Author:}

Nihan Cüzdan MD, Balikesir Ataturk

City Hospital, Clinic of Rheumatology,

Balikesir, Turkey

nihancuzdan@hotmail.com

ORCID:

orcid.org/0000-0001-7238-657X

Keywords: Ankylosing spondylitis, arthritis, inflammation, rheumatic diseases, rheumatoid arthritis, vitamin D

\begin{abstract}
Aims: The aim of this study was to compare serum vitamin D levels in patients with inflammatory rheumatic diseases and non-inflammatory musculoskeletal disorders presenting with pain.

Methods: Patients were divided into three groups. Group 1 consisted of patients with inflammatory rheumatic diseases; group 2, non-inflammatory musculoskeletal disorders; and group 3, healthy controls. The plasma levels of $25(\mathrm{OH}) \mathrm{D}<10 \mathrm{ng} / \mathrm{mL}$ were accepted as vitamin D insufficiency. Correlation between pain intensity (visual analog scale), erythrocyte sedimentation rate (ESR), C-reactive protein (CRP) levels, disease activity score 28 (DAS28)CRP for rheumatoid arthritis patients, Bath Ankylosing Spondylitis Disease Activity Index for ankylosing spondylitis patients, and $25(\mathrm{OH}) \mathrm{D}$ levels were analyzed.
\end{abstract}

Results: Eighty-one patients with inflammatory rheumatic diseases (group 1, mean age $=47.8 \pm 12.2$ years), 26 patients with non-inflammatory musculoskeletal disorders (group 2, mean age $=46.6 \pm 4.5$ years), and 36 healthy controls (group 3, mean age $=45.2 \pm 9.2$ years) were included. There was a significant difference among the groups regarding $25(\mathrm{OH}) \mathrm{D}$ levels (group $1=16.4 \pm 11.3 \mathrm{ng} / \mathrm{mL}$, group $2=13.9 \pm 6.4 \mathrm{ng} / \mathrm{mL}$, group $3=20.4 \pm 8.2 \mathrm{ng} / \mathrm{mL})(p=0.031) .25(\mathrm{OH}) \mathrm{D}$ levels in patients with non-inflammatory musculoskeletal diseases were lower than the healthy controls $(p=0.003)$. No significant difference was seen between two patient groups $(p=0.334)$. There was a weak-to-moderate negative correlation between pain intensity, ESR, CRP, DAS28CRP and 25(OH)D levels $(r=-0.302, p=0.002 ; r=-0.259, p=0.020 ; r=-0.259, p=0.020 ; r=-0.374$, $\mathrm{p}=0.022$ respectively).

Conclusions: The results of this study are important in terms of routine monitoring and replacement of vitamin $D$ in case of deficiency in chronic inflammatory and non-inflammatory rheumatic diseases presenting with pain.

\section{Introduction}

Vitamin $D$ is synthesized in the skin in the presence of sunlight and then metabolized into an active metabolic form in the liver, kidney and peripheral immune/inflammatory cells. Active metabolite of vitamin $D\left[1,25(\mathrm{OH})_{2} \mathrm{D}\right]$ is important for bone metabolism and function of neuromuscular system. The deficiency of this hormone is mainly associated with osteoporosis in adults and rickets in pediatric population. Also, the deficiency of this hormone is observed to be associated with different forms of non-inflammatory chronic pain conditions (1-4). One of the types of non-inflammatory chronic pain is persistent nonspecific musculoskeletal pain, such as non-inflammatory unexplained arthralgia or myalgia, which is seen frequently in rheumatology clinics. In this type of chronic pain conditions, reaching a precise diagnosis and decision on an effective treatment can be quite challenging for the clinician.

Vitamin $D$ is also known to have a role in the regulation of immune system. Active metabolite of vitamin D appears to have an immunosuppressive effect and to play a role in the autoimmune diseases (5). It is not so evident that the deficiency of vitamin $D$ has causality for rheumatic diseases, whereas the prevalence is claimed to be high (6-8). Several surveys indicated that patients with rheumatoid arthritis (RA), ankylosing spondylitis (AS), scleroderma, polymyositis, dermatomyositis and systemic lupus 
erythematosus had lower levels of $25(\mathrm{OH}) \mathrm{D}$ than the healthy population $(6,7)$. Also, there are a number of studies in which vitamin $\mathrm{D}$ was reported to be related to the disease activity in patients with inflammatory rheumatologic diseases (9-11). Among these, two of the mostly studied rheumatologic diseases are RA and AS. The initiation and progression of these diseases have been thought to be associated with the plasma values of vitamin D (12).

To the best of our knowledge, no comparative analysis of serum vitamin $D$ exists between inflammatory and noninflammatory musculoskeletal diseases. The primary aim of this study was to investigate plasma vitamin D levels among patients with inflammatory rheumatic diseases and those with non-inflammatory musculoskeletal disorders who presented with pain, and to compare vitamin D levels with healthy controls. The secondary aim was to determine the relationship between disease activity of inflammatory rheumatologic diseases and vitamin D levels.

\section{Methods}

\section{Subjects}

This retrospective case-control study was conducted between the dates of December 2015 and March 2016. Patients with inflammatory and non-inflammatory rheumatic diseases along with the healthy controls, who were referred to the physical medicine and rehabilitation outpatient clinic, were retrospectively screened up to the date of January 2009.

Group 1 consisted of patients with inflammatory rheumatic diseases including RA and AS. The diagnoses of RA and AS were based upon the 2010 ACR/EULAR criteria and 1984 modified New York criteria, respectively.

Group 2 included the patients with non-inflammatory musculoskeletal disorders, such as unexplained myalgia, bone pain and arthralgia without tenderness, erythema, limitation of motion or swelling persisting for more than three months, which could not be attributed to any precise disease based on clinical, radiographic and laboratory examinations.

Group 3 was comprised of healthy controls.

Patients with fibromyalgia, osteoarthritis, chronic kidney and/ or liver disease, malignancy, inflammatory rheumatic diseases other than RA and AS, malabsorption syndromes, pregnancy, and individuals who were on corticosteroid regimen or vitamin $D$ supplementation were excluded from the study.

\section{Measurements}

All descriptive, clinical and laboratory data were recruited from the hospital database. Pain levels which were measured with visual analog scale (VAS); tender and swollen joint counts (SJC); disease activity, which was recorded as disease activity score 28 (DAS28)-C-reactive protein (CRP) score for RA and Bath Ankylosing Spondylitis Disease Activity Index (BASDAI) score for AS, were obtained from patients' medical records.

The baseline $25(\mathrm{OH}) \mathrm{D}$ levels prior to any vitamin $\mathrm{D}$ supplementation, which were measured with the high performance liquid chromatography technique using chromo system kit, were noted. The plasma levels of $25(\mathrm{OH}) \mathrm{D}>30$ $\mathrm{ng} / \mathrm{mL}$ were considered as optimal vitamin $D$ status, whereas levels $<10 \mathrm{ng} / \mathrm{mL}$ were accepted as vitamin D insufficiency (13). Concurrent erythrocyte sedimentation rate (ESR) and CRP levels of the patients with inflammatory rheumatic diseases were also documented.

\section{Statistical Analysis}

Data evaluation was conducted with Statistical Package for the Social Sciences (SPSS) 17.0 for Windows (SPSS Inc., Chicago, IL, USA). Descriptive statistics was performed to calculate mean and standard deviation, median and range values. Normality of the variables was checked by the Kolmogorov-Smirnov Test. Two group comparisons and multiple group comparisons were performed via the Mann-Whitney $U$ and Kruskal-Wallis tests, respectively. Values are given as mean ( \pm standard deviation). The Spearman correlation analysis was used in order to evaluate the associations between variables. The correlation coefficient $(r)$ value of $0-0.24$ was considered as "no correlation", 0.25-0.49 as "weak", 0.5-0.74 as "moderate", and $0.75-1$ as "strong"correlation. $\mathrm{P}<0.05$ was considered as statistically significant.

Ethical approval of the study was obtained from the Cukurova University Faculty of Medicine Local Ethics Committee (protocol number: 2014/34).

\section{Results}

Eighty-one patients with inflammatory rheumatic diseases (group 1, mean age $=47.8 \pm 12.2$ years), 26 patients with noninflammatory musculoskeletal disorders (group 2, mean age $=46.6 \pm 4.5$ years) and 36 healthy controls (group 3, mean age $=45.2 \pm 9.2$ years) were included in the study. The demographic, clinical and laboratory results of the patients are summarized in Table 1.

The mean $25(\mathrm{OH}) \mathrm{D}$ levels were measured as $16.4 \pm 11.3 \mathrm{ng} /$ $\mathrm{mL}$ in group $1(15.51 \pm 12.15 \mathrm{ng} / \mathrm{mL}$ in RA patients, 40.63 \pm 9.29 in AS patients), $13.9 \pm 6.4 \mathrm{ng} / \mathrm{mL}$ in group 2, and $20.4 \pm 8.2 \mathrm{ng} /$ $\mathrm{mL}$ in group 3. According to one-way ANOVA test, $25(\mathrm{OH}) \mathrm{D}$ levels significantly differed among three groups $(p=0.031)$. In post-hoc analysis, the level of vitamin $D$ in the non-inflammatory musculoskeletal disease group was statistically significantly lower than in the healthy control group $(p=0.003)$, whereas there was no statistically significant difference between the inflammatory disease group and other groups (group 1-2, $p=0.334$; group $1-3, p=0.087$ ). The percentages of vitamin $D$ 


\begin{tabular}{|c|c|c|c|c|c|c|}
\hline \multirow{2}{*}{\multicolumn{2}{|c|}{ Rheumatoid arthritis }} & \multicolumn{2}{|l|}{ Group 1} & \multirow{2}{*}{$\begin{array}{l}\text { Group } 2 \\
\text { Healthy control }\end{array}$} & \multirow[t]{2}{*}{ Group 3} & \multirow[t]{2}{*}{$\mathrm{p}^{\#}$} \\
\hline & & $\begin{array}{l}\text { Ankylosing } \\
\text { spondylitis }\end{array}$ & $\begin{array}{l}\text { Non-inflammatory } \\
\text { musculoskeletal } \\
\text { pain }\end{array}$ & & & \\
\hline \multicolumn{2}{|c|}{ Age (years) (mean \pm SD) } & $54.78 \pm 10.46$ & $40.63 \pm 9.29$ & $46.58 \pm 4.53$ & $45.23 \pm 9.223$ & 0.473 \\
\hline \multicolumn{2}{|c|}{ Gender [female (\%)] } & $39(95.1 \%)$ & $22(55 \%)$ & $19(73.1 \%)$ & $18(51.4 \%)$ & $0.034^{*}$ \\
\hline \multicolumn{2}{|c|}{$\begin{array}{l}\text { Vitamin D levels } \\
(\text { mean } \pm \text { SD) }(\mathrm{ng} / \mathrm{mL})\end{array}$} & $15.51 \pm 12.15$ & $17.31 \pm 10.39$ & $13.869 \pm 6.439$ & $20.41 \pm 8.22$ & $0.031^{*}$ \\
\hline \multicolumn{2}{|c|}{$\begin{array}{l}\text { Sedimentation rate } \\
(\text { mean } \pm \mathrm{SD})(\mathrm{mm} / \mathrm{h})\end{array}$} & $32.00(20.00-45.50)$ & $\begin{array}{l}24.50(11.00- \\
36.50)\end{array}$ & - & - & \\
\hline \multicolumn{2}{|c|}{ CRP $($ mean $\pm \mathrm{SD})(\mathrm{mg} / \mathrm{dL})$} & $0.80(0.30-1.93)$ & $0.73(0.37-1.76)$ & - & - & \\
\hline \multicolumn{2}{|c|}{$\mathrm{RF}($ mean $\pm \mathrm{SD})(\mathrm{IU} / \mathrm{mL})$} & $22.40(20.00-55.60)$ & $\begin{array}{l}20.75(20.00- \\
21.50)\end{array}$ & - & - & \\
\hline \multicolumn{2}{|c|}{ DAS28-CRP } & $3.16 \pm 1.59$ & - & - & - & \\
\hline \multicolumn{2}{|c|}{ BASDAI score } & - & $3.69(2.70-5.82)$ & - & - & \\
\hline \multicolumn{2}{|c|}{ PTH levels (mean \pm SD) $(\mathrm{pg} / \mathrm{mL})$} & $51.22 \pm 34.26$ & $47.49 \pm 32.40$ & $60.28 \pm 32.40$ & - & \\
\hline \multicolumn{2}{|c|}{ Calcium levels (mean $\pm \mathrm{SD}$ ) (mg/dL) } & $9.28 \pm 0.43$ & $9.24 \pm 0.51$ & $8.90 \pm 0.53$ & - & \\
\hline \multicolumn{2}{|c|}{ ALP [median (25-75)] (U/L) } & $64.0(55.0-85.0)$ & $67.0(56.0-88.5)$ & $69.0(58.0-91.5)$ & - & \\
\hline \multicolumn{2}{|c|}{ SJC n, [median (25-75)] } & $0.0(0.0-2.5)$ & - & - & - & \\
\hline \multicolumn{2}{|c|}{ TJC n, [median (25-75)] } & $1.5(0.0-6.5)$ & - & - & - & \\
\hline \multicolumn{2}{|c|}{ VAS n, [median (25-75)] } & $5.00(2.00-7.00)$ & $4.00(3.00-6.75)$ & $4.00(3.00-5.25)$ & - & \\
\hline \multirow{3}{*}{ Medication } & NSAID n, \% & $3(7.3 \%)$ & $12(30 \%)$ & - & - & \\
\hline & B.DMARD n, \% & $3(7.3 \%)$ & $10(25 \%)$ & - & - & \\
\hline & S.DMARD n, \% & $35(85.4 \%)$ & $18(45 \%)$ & - & - & \\
\hline \multicolumn{7}{|c|}{$\begin{array}{l}\text { *P<0.05 is considered statistically significant. } \\
\text { \#P values represent for the comparisons between } 3 \text { groups (group 1, group } 2 \text {, group 3). } \\
\text { SD: Standard deviation, CRP: C-reactive protein, RF: Rheumatoid factor, DAS28-CRP: Disease activity score for rheumatoid arthritis, BASDAl: Bath Ankylosing } \\
\text { Spondylitis Disease Activity Index, PTH: Parathyroid hormone levels, ALP: Alkaline phosphatase, SJC: Swollen joint count, TJC: Tender joint count, VAS: Visual analog } \\
\text { scale, NSAID: Non-steroidal anti-inflammatory drugs, B.DMARD: Biological disease modifying anti-rheumatic drugs, S.DMARD: Synthetic disease modifying anti- } \\
\text { rheumatic drugs }\end{array}$} \\
\hline
\end{tabular}

insufficiency [25(OH)D $<10 \mathrm{ng} / \mathrm{mL}$ ] in group 1 (RA/AS), 2 and 3 were $29.7 \%$ (39\%/25\%), $23.1 \%$ and $8.6 \%$, respectively.

VAS values were found to be similar in RA, AS, and nonspecific musculoskeletal pain patients $(p=0.720)$. Vitamin $D$ levels had no difference between female $(17.01 \pm 11.15 \mathrm{ng} / \mathrm{mL})$ and male $(17.74 \pm 7.03 \mathrm{ng} / \mathrm{mL})$ patients $(\mathrm{p}=0.862)$.

We found weak-to-moderate negative correlation between VAS, SJC, ESR, CRP, DAS28-CRP and 25(OH)D levels $(r=-0.302, p=0.002 ; \quad r=-0.389, p=0.045 ; \quad r=-0.259, p=0.020$; $r=-0.259, \quad p=0.020 ; \quad r=-0.374, \quad p=0.022 ;$ respectively). No correlation was found between vitamin $D$ levels and BASDAI scores $(p=0.913)($ Table 2$)$.

\section{Discussion}

The findings of the study revealed that i) patients with non-inflammatory musculoskeletal conditions had significantly lower vitamin $\mathrm{D}$ levels when compared to the patients with the inflammatory diseases and the healthy controls, ii) vitamin $D$ had a weak correlation with inflammatory markers and disease

\begin{tabular}{llll|}
\hline \multicolumn{3}{|l}{$\begin{array}{l}\text { Table 2. Correlation analysis between pain, inflammation } \\
\text { markers, disease activity indexes and }\end{array}$} & \multicolumn{1}{l}{ 25(OH)D levels } \\
\hline 25(OH)D levels & $\mathbf{r}$ & $\mathbf{p}$ \\
\hline Visual analog scale (pain) & -0.302 & $0.002^{*}$ \\
\hline Swollen joint count & -0.389 & $0.045^{*}$ \\
\hline Erythrocyte sedimentation rate & -0.259 & $0.020^{*}$ \\
\hline CRP & -0.259 & $0.020^{*}$ \\
\hline Disease Activity Score 28-CRP & -0.374 & $0.022^{*}$ \\
\hline $\begin{array}{l}\text { Bath Ankylosing Spondylitis Disease } \\
\text { Activity Index }\end{array}$ & -0.214 & 0.913 \\
\hline $\begin{array}{l}{ }^{*} \mathrm{p}<0.05 \text { is considered as statistically significant. } \\
\text { CRP: C-reactive protein }\end{array}$ & & \\
\hline
\end{tabular}

activity parameters in patients with inflammatory rheumatic diseases and also with pain intensity in all groups.

Both genetic and environmental factors play a role in the pathophysiology of rheumatic diseases. As an environmental compound, the deficiency of vitamin $D$ appears to be associated with the initiation and progression of the disease in patients 
with both RA and AS. A study conducted in the Asian region demonstrated that $65 \%$ of the RA patients had vitamin D levels below $30 \mathrm{ng} / \mathrm{mL}$ (14). Sahebari et al. (15) showed low levels of vitamin $D$ even among the early-diagnosed RA patients. Furthermore, Merlino et al. (16) suggested that vitamin D supply to RA patients had an impact on lowering the incidence of RA. Similar to RA patients, studies conducted on AS patients have shown that low serum vitamin $D$ profile is a common finding in also AS population. Zhao et al. (17), in their systemic review, addressed several cross-sectional studies, which revealed that AS was related to low vitamin D concentrations. Also, a recent meta-analysis has showed that the activation of AS is inversely correlated with $25(\mathrm{OH}) \mathrm{D}$ levels and higher serum vitamin $\mathrm{D}$ concentrations might decrease the risk of AS (18).

Our results are consistent with the general opinion that low vitamin $\mathrm{D}$ levels are commonly seen in inflammatory rheumatic diseases even if it has no statistical significance when compared to the healthy controls. Additionally, the results also indicated that vitamin D level was also significantly lower in patients with non-inflammatory musculoskeletal conditions. We additionally found that vitamin D levels were weakly correlated to inflammatory markers, disease activity in rheumatic conditions and pain intensity in all groups. These findings raise a number of questions: Is the vitamin $D$ deficiency in inflammatory rheumatic diseases independent from inflammation? Is there a common mechanism that explains the decrement of vitamin $D$ in inflammatory and non-inflammatory rheumatic conditions?

There are several observational studies suggesting an association between vitamin $\mathrm{D}$ levels and inflammatory markers $(19,20)$. However, these studies are mostly on specific patient groups; thus, it cannot be generated to all population. According to a review written by da Silva and Rudkowska (20), studies investigating the association of vitamin $D$ with inflammatory markers have conflicting results. According to a meta-analysis in RA patients, serum vitamin D level was found to be significantly low in patients with $R A$, vitamin $D$ deficiency was prevalent in RA patients compared to controls, and the vitamin $\mathrm{D}$ level correlated inversely with RA activity (21). However, a recent study showed opposite results in which they found similar levels of $25(\mathrm{OH}) \mathrm{D}$ levels in the RA patients with age- and gender-matched healthy controls, and no association with joint damage and disease activity (22). Similarly, the studies in AS are not completely in agreement about a possible relation between poor vitamin disease activity parameters and serum vitamin D levels (23). In our study, we found a weak correlation of vitamin $D$ with disease activity in RA, whereas no correlation was found with disease activity of AS patients. One should remember that pain is the common component of disease activity indexes and affects patients' global health. Therefore, it can raise the question whether the relation might be caused by this component rather than the inflammation itself.
There is little evidence in the literature regarding the relationship between vitamin $\mathrm{D}$ deficiency and non-inflammatory musculoskeletal conditions (24-26). Again, pain-being the common ground of all these conditions emerges as a variable, which might explain the relation of vitamin $D$ with both noninflammatory and inflammatory musculoskeletal diseases. Verifying this theory, a study conducted on patients with nonspecific musculoskeletal pain showed that vitamin $D$ deficiency was as high as $95.4 \%$ and pain responded to vitamin D supplementation in majority of the vitamin $D$ deficient patients (27). According to a review published in 2015, vitamin D was believed to have beneficial effect over placebo in chronic pain (28). In the study of Kumar et al. (29), in which they investigated the vitamin $D$ levels in non-inflammatory musculoskeletal complaints, they found low vitamin $D$ level was frequently the sole cause of polyarthralgia, myalgia, bone pain and chronic widespread pain in patients. In their study, they also observed $75 \%$ low vitamin D levels in healthy population. Similar results were reached in the study of Plotnikoff and Quigley (4), where they showed severe hypovitaminosis $D$ in patients with nonspecific musculoskeletal pain. In our study, we observed vitamin $\mathrm{D}$ deficiency in both inflammatory and non-inflammatory painful rheumatic conditions, but significantly lower vitamin $D$ levels in non-inflammatory musculoskeletal conditions referring to rheumatology clinics with chronic pain. All these studies including the present study confirm the impact of vitamin $\mathrm{D}$ on the pathophysiology of pain. Vitamin $\mathrm{D}$ can modulate neuronal excitability, play a role in astrocyte detoxification, limit macrophage colony stimulating factor, and decrease macrophage induced inflammation; thus, has a potential of inhibiting pain formation $(24,28)$.

The strong points of the present study are; i) comparing the vitamin $\mathrm{D}$ levels in both inflammatory and non-inflammatory musculoskeletal conditions with healthy controls, ii) being able to record the baseline $25(\mathrm{OH}) \mathrm{D}$ levels prior to any vitamin $\mathrm{D}$ supplementation therapy, and ii) having enough sample size to allow between group comparisons. However, several limitations exist, as well. As a result of its retrospective design, confounders of vitamin D deficiency (such as, daily exposure to sunlight, physical activity level etc.) could not be obtained from the database. There was a gender difference between the groups; albeit, the vitamin $D$ levels were similar between female and male patients.

\section{Conclusion}

In conclusion, low vitamin $\mathrm{D}$ level is common in both inflammatory and non-inflammatory rheumatic diseases. Thus, routine monitoring and optimization of vitamin $D$ might be beneficial in all patients presenting with pain. Future prospective trials taking all confounders of vitamin $D$ into account are needed in order to confirm the results of this study. 


\section{Ethics}

Ethics Committee Approval: Ethical approval of the study was obtained from Cukurova University Faculty of Medicine Ethics Committee (protocol number: 2014/34).

Informed Consent: Retrospective case-control study.

Peer-review: Externally peer-reviewed.

\section{Authorship Contributions}

Surgical and Medical Practices: N.C., I.C.B., S.B., T.S., Concept: N.C., İ.C.B., S.B., T.S., Design: N.C., I.C.B., S.B., T.S., Data Collection or Processing: N.C., I.C.B., S.B., T.S., Analysis or Interpretation: N.C., I.C.B., S.B., T.S., Literature Search: N.C., I.C.B., S.B., T.S., Writing: N.C., İ.C.B., S.B., T.S.

Conflict of Interest: No conflict of interest was declared by the authors.

Financial Disclosure: The authors declared that this study received no financial support.

\section{References}

1. Atherton K, Berry DJ, Parsons T, Macfarlane GJ, Power C, Hypponen E. Vitamin D and chronic widespread pain in a white middle-aged british population: Evidence from a cross-sectional population survey. Ann Rheum Dis. 2009;68:817-822.

2. Lotfi A, Abdel-Nasser AM, Hamdy A, Omran AA, El-Rehany MA. Hypovitaminosis D in female patients with chronic low back pain. Clin Rheumatol. 2007;26:1895-1901.

3. Mouyis M, Ostor AJ, Crisp AJ, et al. Hypovitaminosis $\mathrm{D}$ among rheumatology outpatients in clinical practice. Rheumatology. 2008;47:1348-1351.

4. Plotnikoff GA, Quigley JM. Prevalence of severe hypovitaminosis $D$ in patients with persistent, nonspecific musculoskeletal pain. Mayo Clin Proc. 2003;78:1463-1470.

5. Cantorna MT, Yu S, Bruce D. The paradoxical effects of vitamin D on type 1 mediated immunity. Mol Aspects Med. 2008;29:369-375.

6. Cutolo M. Vitamin D or hormone D deficiency in autoimmune rheumatic diseases, including undifferentiated connective tissue disease. Arthritis Res Ther. 2008;10:123.

7. Pelajo CF, Lopez-Benitez JM, Miller LC. Vitamin D and autoimmune rheumatologic disorders. Autoimmun Rev 2010;9:507-510.

8. Haroon M, Bond U, Quillinan N, Phelan MJ, Regan MJ. The prevalence of vitamin $D$ deficiency in consecutive new patients seen over a 6-month period in general rheumatology clinics. Clinical Rheumatology. 2010;30:789794.

9. Erten S, Kucuksahin O, Sahin A, Altunoglu A, Akyol M, Koca C. Decreased plasma vitamin D levels in patients with undifferentiated spondyloarthritis and ankylosing spondylitis. Intern Med. 2013;52:339-344.
10. Cutolo M, Otsa K, Uprus M, Paolino S, Seriolo B. Vitamin D in rheumatoid arthritis. Autoimmun Rev. 2007;7:59-64.

11. Kostoglou-Athanassiou I, Athanassiou P, Lyraki A, Raftakis I, Antoniadis C. Vitamin D and rheumatoid arthritis. Ther Adv Endocrinol Metab. 2012;3:181-187.

12. Grazio S, Naglić DB, Anić B, et al. Vitamin D serum level, disease activity and functional ability in different rheumatic patients. Am J Med Sci. 2015;349:46-49.

13. Spiro A, Buttriss JL. Vitamin D: An overview of vitamin D status and intake in Europe. Nutr Bull. 2014;39:322-350.

14. Quraishi MK, Badsha H. Rheumatoid arthritis disease activity and vitamin $D$ deficiency in an Asian resident population. Int J Rheum Dis. 2016;19:348-354.

15. Sahebari M, Mirfeizi Z, Rezaieyazdi Z, Rafatpanah $\mathrm{H}$, Goshyeshi L. 25(OH) vitamin D serum values and rheumatoid arthritis disease activity (DAS28 ESR). Caspian J Intern Med. 2014;5:148-155.

16. Merlino LA, Curtis J, Mikulis TR, Cerhan JR, Criswell LA, Saag KG. Vitamin D intake is inversely associated with rheumatoid arthritis: results from the lowa Women's Health Study. Arthritis Rheum. 2004;50:72-77.

17. Zhao S, Duffield SJ, Moots RJ, Goodson NJ. Systematic review of association between vitamin $D$ levels and susceptibility and disease activity of ankylosing spondylitis. Rheumatology (Oxford). 2014;53:1595-1603.

18. Cai G, Wang L, Fan D, et al. Vitamin D in ankylosing spondylitis: review and meta-analysis. Clin Chim Acta. 2015;438:316-322.

19. Abourazzak FE, Talbi S, Aradoini N, Berrada K, Keita $S$, Hazry T. 25-Hydroxy vitamin $D$ and its relationship with clinical and laboratory parameters in patients with rheumatoid arthritis. Clin Rheumatol. 2015;34:353-357.

20. da Silva MS, Rudkowska I. Dairy nutrients and their effect on inflammatory profile in molecular studies. Mol Nutr Food Res. 2015;59:1249-1263.

21. Lee $\mathrm{YH}, \mathrm{Bae} \mathrm{SC}$. Vitamin D level in rheumatoid arthritis and its correlation with the disease activity: a meta-analysis. Clin Exp Rheumatol. 2016;34:827-833.

22. Polasik K, Piotrowska E, Lipińska B, Witkowski JM, Bryl E, Tukaj S. Vitamin D status in patients with rheumatoid arthritis: a correlation analysis with disease activity and progression, as well as serum IL-6 levels. Acta Biochim Pol. 2017;64:667-670.

23. Crotti C, Becciolini A, Biggioggero M, Favalli EG. Vitamin $\mathrm{D}$ and spondyloarthritis: review of the literature. The Open Rheum Journal. 2020;12:214-225.

24. Haroon M, Fitzgerald O. Vitamin D deficiency: subclinical and clinical consequences on musculoskeletal health. Current Rheumatol Rep. 2012;14:286-293.

25. Ghai B, Bansal D, Kapil G, Kanukula R, Lavudiya S, Sachdeva N. High prevalence of hypovitaminosis D in Indian chronic low back pain patients. Pain Physician. 2015;18:E853-E862. 
26. de Torrenté de la Jara G, Pécoud A, Favrat B. Female asylum seekers with musculoskeletal pain: the importance of diagnosis and treatment of hypovitaminosus D. BMC Fam Pract. 2006;7:4.

27. Abbasi M, Hashemipour S, Hajmanuchehri F, Kazemifar AM. Is vitamin D deficiency associated with non-specific musculoskeletal pain? Glob J Health Sci. 2012;5:107-111.
28. Shipton EA, Shipton EE. Vitamin D and Pain: Vitamin D and its role in the aetiology and maintenance of chronic pain states and associated comorbidities. Pain Res Treat. 2015;2015:904967.

29. Kumar A, Gopal H, Khamkar K, et al. Vitamin D deficiency as the primary cause of musculoskeletal complaints in patients referred to rheumatology clinic: A clinical study. Indian J of Rheum. 2012;7:199-203. 